\title{
A low power consumption radar system for measuring ice thickness and snow/firn accumulation in Antarctica
}

\author{
José A. URIBE, ${ }^{1}$ Rodrigo ZAMORA, ${ }^{1}$ Guisella GACITÚA, ${ }^{1}$ Andrés RIVERA, ${ }^{1,3}$ \\ David ULLOA ${ }^{2}$ \\ ${ }^{1}$ Glaciology and Climate Change, Centro de Estudios Científicos (CECs), Valdivia, Chile \\ E-mail: juribeparada@cecs.cl \\ ${ }^{2}$ Unmanned Industrial Ltda., Valdivia, Chile \\ ${ }^{3}$ Department of Geography, Universidad de Chile, Santiago, Chile
}

\begin{abstract}
In order to measure total ice thickness and surface snow accumulation in Antarctica, we have designed and built a surveying system comprising two types of radar. This system is aimed at having low power consumption, low weight/volume and low construction cost. The system has a pulsecompression radar to measure ice thickness, and a frequency-modulated continuous wave (FM-CW) radar designed to measure hundreds of meters of surface snow/firn layers with high resolution. The pulsecompression radar operates at $155 \mathrm{MHz}, 20 \mathrm{MHz}$ of bandwidth; and the FM-CW radar operates from 550 to $900 \mathrm{MHz}$. The system was tested in December 2010 at Union Glacier $\left(79^{\circ} 46^{\prime} \mathrm{S}, 83^{\circ} 24^{\prime} \mathrm{W}\right)$, West Antarctica, during an oversnow campaign, where Union and other nearby glaciers (Schanz, Schneider and Balish) were covered through $82 \mathrm{~km}$ of track. Ice thickness of $1540 \mathrm{~m}$ and snow/firn thickness of $120 \mathrm{~m}$ were detected in the area. The collected data allowed the subglacial topography, internal ice structure, isochronous and the snow/ice boundary layer to be detected. Here we describe radar electronics, their main features and some of the results obtained during the first test campaign. Further improvements will focus on the adaptation of the system to be implemented on board airplane platforms.
\end{abstract}

KEYWORDS: Antarctic glaciology, glaciological instruments and methods, ground-penetrating radar, polar firn, radio-echo sounding

\section{INTRODUCTION}

Radio-echo sounding (RES) has been a useful method in glaciology since the discovery of the transparency of cold ice for the propagation of electromagnetic waves (Waite and Schmidt, 1962). Radar applications in polar ice sheets have included the study of ice thickness, subglacial topography, subglacial roughness, subglacial geology and subglacial lakes (Peters and others, 2005; Vaughan and others, 2007). Radar data have also been used to detect internal ice layers, estimate glacier mass balance and characterize ice dynamics (Bingham and Siegert, 2007). In snow and firn, radars have been used to determine thickness, stratigraphy layers and other properties (Plewes and Hubbard, 2001). Because of the versatility of RES, numerous radar types have been developed for studying ice masses. Historical reviews of radar systems developed for glaciological purposes are provided by Gogineni and others (1998) and Plewes and Hubbard (2001), for example.

Normally, radars designed to survey ice thickness are completely independent of high-resolution radars aimed at measuring snow accumulation (Gogineni and others, 2001; Kanagaratnam and others, 2004; Raney and others, 2008; Panzer and others, 2013). However, a complete package multi-frequency radar system, focused on wide-coverage airborne survey, has been developed by the University of Kansas, USA. This illustrated the importance of multispectral radar data to characterize the entire ice column (RodríguezMorales and others, 2013).

In this paper, we present a design of a VHF/UHF ground radar system aimed at measuring cold ice thickness and highresolution surface snow/firn. This system is intended to survey rough areas using ground or airborne platforms. Its main advantages are its low power consumption and low weight/ volume, which were achieved by taking into account, during the design stage, the integration of a pulse-compression radar and a frequency-modulated continuous wave (FM-CW) radar, as well as the complete design of each section. We also reduced the implementation costs in designing and building each stage. Low power and compact design are important considerations for long oversnow traverses, as well as being a key factor for future implementation of radars on unmanned aerial vehicles (UAV), a configuration that can reduce operational costs for glaciological measurements (Blake and others, 2008; Remy and others, 2012).

In December 2008, we tested a pulse-compression prototype radar designed to measure ice thickness at Union Glacier $\left(79^{\circ} 46^{\prime} \mathrm{S}, 83^{\circ} 24^{\prime} \mathrm{W}\right)$ and the Horseshoe Valley in West Antarctica (Fig. 1) (Rivera and others, 2010). Thanks to this experience, the upgraded radar presented in this paper was used at Union Glacier, during an oversnow traverse carried out in December 2010. During this campaign, we performed ice thickness and snow/firn measurements along Union, Schanz, Schneider and Balish glaciers (Fig. 8); results are presented here to show the performance of the radar system. These data complement the glaciological baseline of Union Glacier and improve knowledge of the basic characteristics of nearby glaciers, where only BEDMAP data (Lythe and others, 2001) were available until our first surveys (Rivera and others, 2010).

The Union Glacier area was selected as a testing site because of its complex surface and subglacial topography, the presence of a blue-ice area and the availability of in situ 


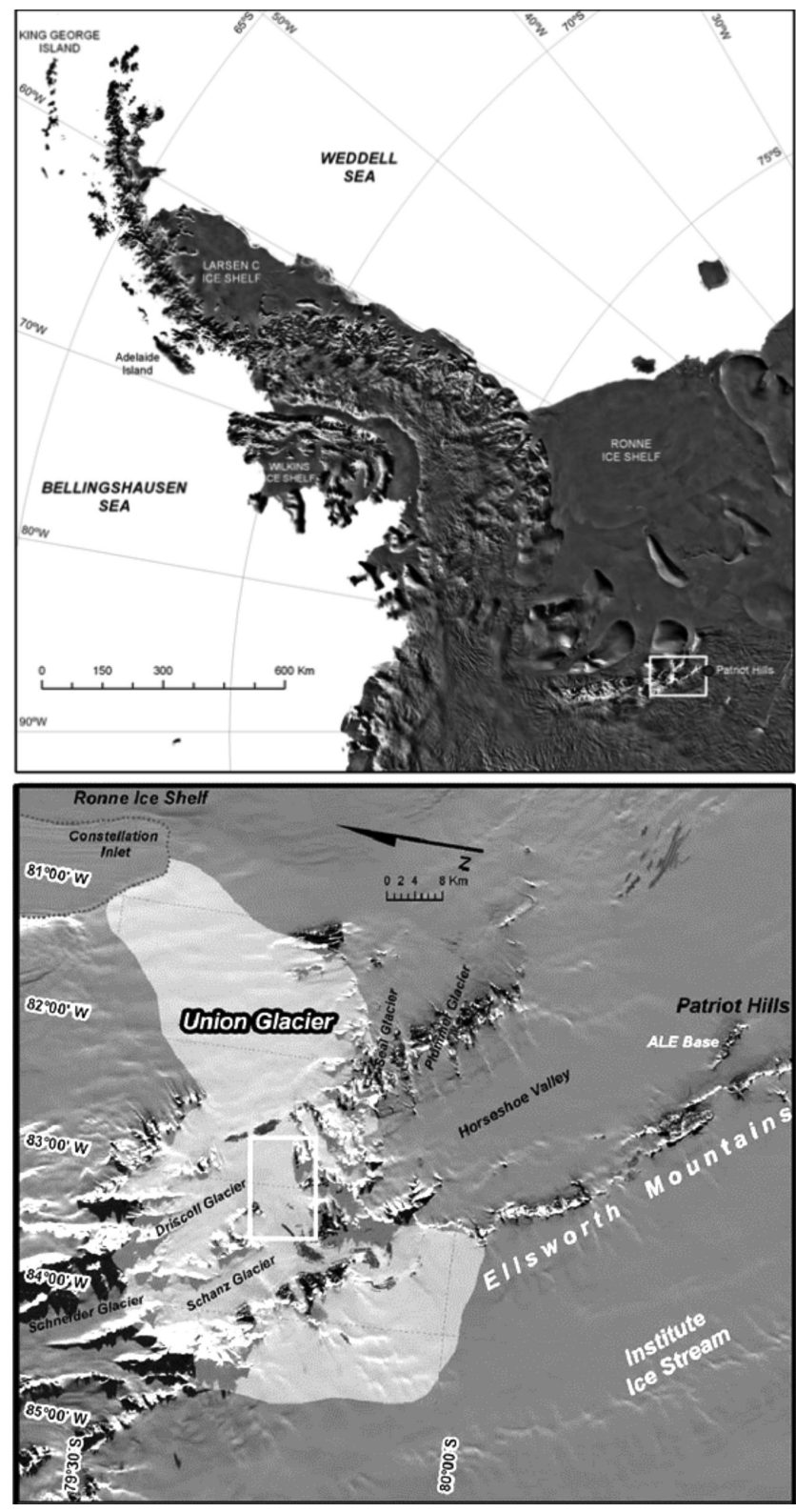

Fig. 1. Location map of the testing site at Union Glacier (box in lower image).

mass-balance and ice-dynamic data collection. This area is located only $40 \mathrm{~km}$ upstream of the local grounding line at Constellation Inlet, in the Ronne Ice Shelf. The proximity of our study area to the local grounding line zone is of interest due to possible upward grounding line migrations already forecast in the region (Hellmer and others, 2012). Hence, contributions to build up a glaciological baseline of Union Glacier are important for understanding possible future glacier dynamic responses to ongoing atmospheric and oceanic changes.

Here we present the technical details of our system including the signal generation, RF systems, the RF power amplifier and the digital data capture systems, as well as some of the results obtained.

\section{SYSTEM OVERVIEW}

The pulse-compression method permits one to improve the range resolution and the signal-to-noise ratio (SNR) that would have been obtained from the uncompressed pulse
Table 1. Pulse-compression radar parameters

\begin{tabular}{lcc}
\hline Description & Value & Unit \\
\hline Frequency range & $145-165$ & $\mathrm{MHz}$ \\
Resolution in ice* & 4.2 & $\mathrm{~m}$ \\
Chirp length & $1-10$ & $\mu \mathrm{s}$ \\
Pulse repetition frequency (PRF) & $10(\max )$ & $\mathrm{kHz}$ \\
Peak power & $200(\max )$ & $\mathrm{W}$ \\
Coherent integration & $64-4096$ & traces \\
Trace length & 2048 & $\mathrm{samples}$ \\
Sampling frequency & 40.5 & $\mathrm{MHz}$ \\
Receiver gain & $83.8(\max )$ & $\mathrm{dB}$ \\
Receiver noise figure & 3.3 & $\mathrm{~dB}$ \\
& & \\
\hline
\end{tabular}

*See Discussion section for more details.

Table 2. FM-CW radar parameters

\begin{tabular}{lcc}
\hline Description & Value & Unit \\
\hline Frequency range & $550-900$ & $\mathrm{MHz}$ \\
Resolution in air & 0.5 & $\mathrm{~m}$ \\
PRF & 10 & $\mathrm{kHz}$ \\
Transmitter power & 21 & $\mathrm{dBm}$ \\
Coherent integration & $64-256$ & traces \\
Trace length & 4096 & $\mathrm{samples}$ \\
Range & 480 & $\mathrm{~m}$ \\
Sampling frequency & 45 & $\mathrm{MHz}$ \\
Receiver gain & 80.3 & $\mathrm{~dB}$ \\
Receiver noise figure & 4.1 & $\mathrm{~dB}$ \\
\end{tabular}

waveform. This method uses long chirp-modulated pulses to increase the average transmitted power (Mahafza, 2000). Given the low attenuation of high frequencies in cold ice, it is possible to operate in VHF band, employing common RF amplifiers, electronics components and small antennas. FM$\mathrm{CW}$ radars are often used as high-resolution systems because, despite their high bandwidth, they do not require high-speed data acquisition. Figure 2 shows a reduced block diagram of the overall radar system. The pulse-compression system is based on an Advanced COherent Radar Depth Sounder (ACORDS) system by Namburi (2003), and the FM$\mathrm{CW}$ system is based on the radar presented by Kanagaratnam and others (2004).

The digital system generates the chirp waveform at $155 \mathrm{MHz}$ to the pulse-compression radar transmitter, and the baseband frequency sweep $(50-400 \mathrm{MHz})$ to the FMCW system, through two separate direct digital synthesizer (DDS) systems. It also performs the analog-to-digital conversions of three received analog signals: two signals (channels 1 and 2) from the pulse-compression radar receiver, and the intermediate frequency (IF) signal from the FM-CW radar front-end. The two channel schemes have different amplification gains (low and high gain) of the received signal to increase the dynamic range of the pulsecompression radar. This method was proposed by Namburi (2003) to avoid sensitivity time control (STC) systems.

A geodetic Javad Lexon GPS receiver was used, which provides NMEA183 messages and pulse per second (PPS) signals for precise time marking and basic georeferencing of each radar trace captured and precise georeferencing in post-processing. All digitized data are coherently averaged 


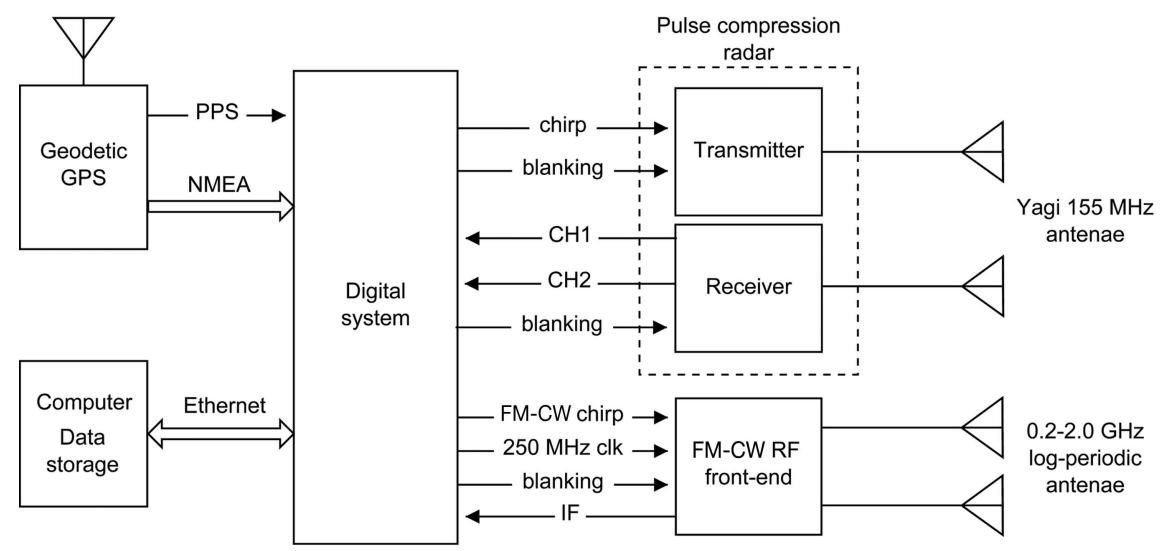

Fig. 2. General block diagram of the radar system.

inside the digital system, then sent to the computer through an Ethernet link, where the raw data are stored. The computer runs a custom program that controls all radar parameters and preprocesses the raw data in real time for viewing purposes. Tables 1 and 2 show the most important parameters of pulse compression and the FM-CW radars.

\section{THE PULSE-COMPRESSION SYSTEM}

\section{Transmitter}

The pulse-compression radar transmitter (Fig. 3) consists of three stages: a pre-amplifier, a power driver amplifier and the final power stage. The power driver amplifier produces a maximum output of $5 \mathrm{~W}$. This amplifier is a custom design based on the BLF242 D-MOS transistor, which was designed to operate at $28 \mathrm{~V}$ in the $145-165 \mathrm{MHz}$ band. The signal amplified by the power driver feeds the input of the power amplifier and is based on a Freescale MRF6V2300N MOSFET transistor that operates at $50 \mathrm{~V}$, which is generated by a switching power supply (VPU-S200-48, CUI Inc). The power amplifier design presented in Figure 3 is a modified version of the schematic presented in the data sheet (http://www.freescale.com/files/rf_if/doc/data_sheet/ MRF6V2300N.pdf), which operates at $220 \mathrm{MHz}$. The input and output matching networks were changed (microstrip lines and capacitors) to tune the amplifier at $155 \mathrm{MHz}$.
Furthermore, trimmer capacitors to the input and output matching networks were added for manual tuning to obtain a flat frequency response from 145 to $165 \mathrm{MHz}$. Finally, after several laboratory tests, we reduced the current polarization of the transistor drain $\left(I_{d q}\right)$ from $900 \mathrm{~mA}$ (data-sheet recommendation) to $100 \mathrm{~mA}$, reducing the total power consumption. With this configuration, we obtained $200 \mathrm{~W}$ of peak power $(10 \mathrm{kHz}$ of pulse repetition frequency (PRF), $10 \mu$ s chirp long) from the transmitter output in the complete 145-165 MHz band.

\section{Receiver}

The receiver (Fig. 4) is designed to produce two outputs from the same receiver antenna with different gains. One output has a low amplification gain, which is used in combination with a short chirp length $(1.0 \mu \mathrm{s})$ to survey the shallow part of the ice (generally to $1 \mathrm{~km}$ depth). The use of short chirp length in this channel is convenient, especially in groundbased surveys, because the blanking circuit in the receiver produces a signal loss in the first 10-100 m. The second output has a high amplification gain, which is used with the long chirp length $(10.0 \mu \mathrm{s})$ to survey the deepest part of the ice (down to $4 \mathrm{~km}$ ).

The receiver antenna is connected to a directional coupler, which obtains a sample of the received signal for the low-gain channel. The main output of the directional

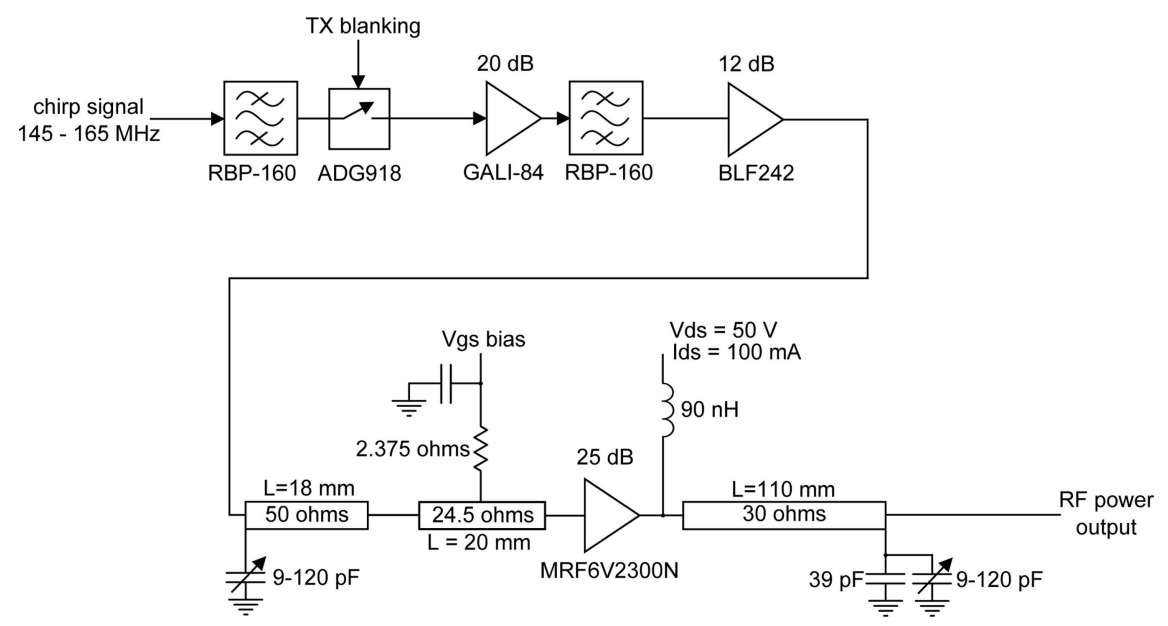

Fig. 3. Block diagram of the pulse-compression transmitter. Only the matching networks of the RF power MOSFET are shown. See the data sheet for details of biasing circuits. 


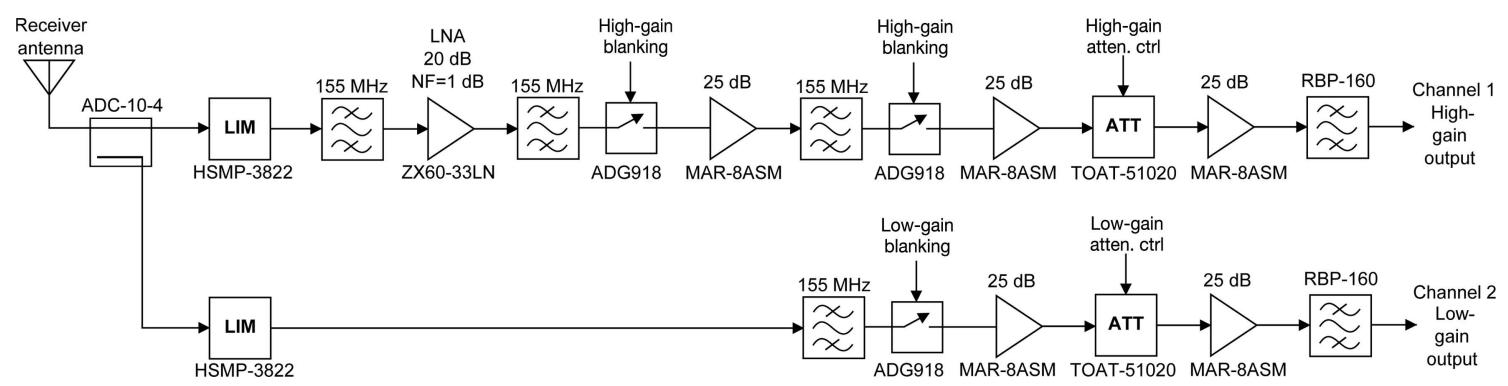

Fig. 4. Block diagram of the two-channel pulse-compression receiver.

coupler is clipped by a PIN diode limiter to protect the input of the next stages from high-level received signals. The following step is a custom Butterworth bandpass filter (order 3 , center frequency $155 \mathrm{MHz}, 40 \mathrm{MHz}$ of bandwidth), which reduces the unwanted out-of-band signals. The filtered signal is then amplified by a Mini-Circuits ZX60-33LN low-noise amplifier (LNA) with $20 \mathrm{~dB}$ of gain and $1 \mathrm{~dB}$ of noise figure. The LNA output feeds the input of an amplifier chain, composed of three MMIC amplifiers each with a gain of $25 \mathrm{~dB}$. This chain contains custom Butterworth bandpass filters for bandwidth restriction, and a digital step attenuator for gain adjustment. This amplification path produces highgain output $(52.8-83.8 \mathrm{~dB})$ and low noise $(3.3 \mathrm{~dB})$. The second amplification path is composed only of two MMIC amplifiers, bandpass filters and another digital step attenuator, which is fed by the coupled output of the directional coupler and produces the low-gain output (1.4-32 dB).

\section{THE FM-CW SYSTEM}

Figure 5 shows a block diagram of the RF section of the FM$\mathrm{CW}$ radar. A $1 \mathrm{GHz}$ direct digital synthesizer (DDS) in the digital section produces a frequency sweep from 50 to $400 \mathrm{MHz}$, which is up-converted to $550-900 \mathrm{MHz}$ by a mixer. This mixer uses a $500 \mathrm{MHz}$ sine signal as a local oscillator (LO), which is generated by doubling a $250 \mathrm{MHz}$ sine reference signal from the digital section. The translated sweep signal is bandpass-filtered to eliminate the lower sideband generated by the mixer and other spurious signals. The signal is then amplified $15 \mathrm{~dB}$, and a sample of this signal is extracted by a directional coupler, where it is used in the receiver mixer. The amplified sweep signal is amplified again by two stages to get the appropriate power to the transmitter antenna. The HELA-10B (Mini-Circuits) power amplifier was used, which is designed for maximum output power of $30 \mathrm{dBm}$ at $50-1000 \mathrm{MHz}$. However, only $21 \mathrm{dBm}$ was used in the field to avoid excessive amplitude signal distortion. At the output of this power stage, we applied the blanking switch (an absorptive RF switch), which disconnects the transmitter antenna during the pulsecompression radar operation. This is necessary because the FM-CW DDS still generates a signal during the pulsecompression radar operation, from which an unwanted signal could be emitted through the FM-CW transmitter antenna, which might interfere with the pulse-compression receiver.

The signal from the receiver antenna is sent to a limiter, a PIN diode, to protect the subsequent stages from highlevel signals. After that, the received signal is bandpassfiltered to eliminate the unwanted signal outside the FM$\mathrm{CW}$ radar bandwidth. The filtered signal is then amplified by the LNA ZX60-33LN and filtered again. This signal is mixed by the receiver mixer, where the sample signal from the directional coupler from the transmitter is used as a LO input. This mixing between the local frequency sweep signal and the received signal produces the beat frequencies, proportional to the range measured. These are filtered by a custom high-pass filter, which is designed to attenuate both the unwanted low-frequency beats and the beat frequency generated by the direct feedthrough between the transmitter and receiver antennas. This filter provides a high attenuation to the beat antenna feedthrough frequency

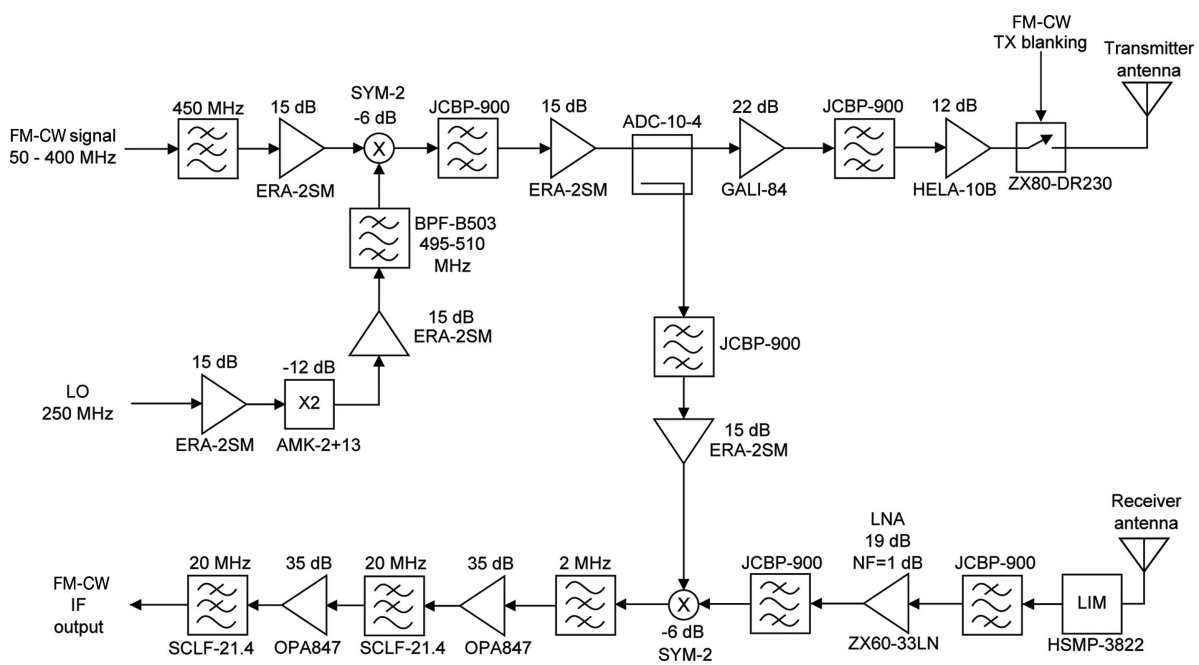

Fig. 5. Block diagram of the FM-CW analog transmitter and receiver. 


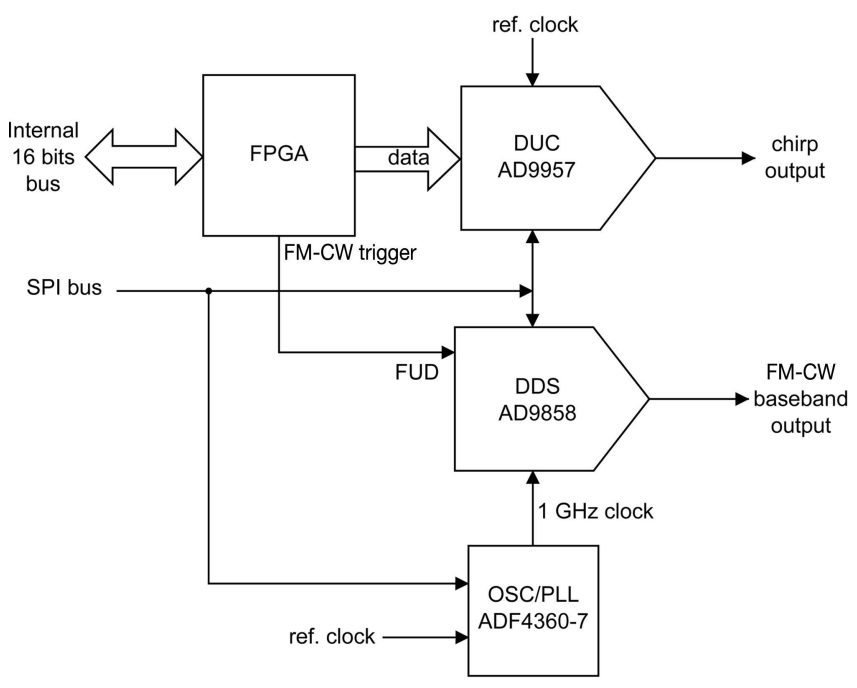

Fig. 6. Block diagram of the radar signal generator.

without excessive ringing. We designed a Gaussian highpass filter, according to Kanagaratnam (2002), for reducing ringing and transient effects, with a frequency cut-off at $2 \mathrm{MHz}$ and with attenuation of $60 \mathrm{~dB}$ at $0.4 \mathrm{MHz}$, which was the expected beat frequency of the antenna feedthrough in the laboratory tests. The following stage is the IF amplifier, which was designed with a gain of $70 \mathrm{~dB}$. This was implemented with two high-speed OPA847 (Texas Instruments) operational amplifiers, each with a gain of $35 \mathrm{~dB}$. According to the maximum range of $480 \mathrm{~m}$ and $10 \mathrm{kHz}$ of PRF established at the design stage, the maximum beat frequency expected is $20 \mathrm{MHz}$.

\section{SIGNAL GENERATION}

The signal source generation for the two radars is set up in the digital section by two different DDS generators (Fig. 6). The signal source generation for the pulse-compression radar is performed by a field programmable gate array (FPGA) and an integrated circuit (IC) AD9957 (Analog Devices). This IC is a digital up-converter (DUC) working at 1 giga-sample per second (GSPS), which includes a 14-bit digital-to-analog converter, a digital quadrature modulator and a numerically controlled oscillator. The waveform for the pulse-compression radar is loaded (in baseband form) by the digital system in an internal memory buffer of the FPGA; the FPGA then continuously sends (at the PRF rate) the buffer content to the DUC, which digitally moves the spectrum of the waveform to the desired central frequency and generates the analog output. In this way, the system can generate any arbitrary waveform from 0.5 to $400 \mathrm{MHz}$, with high linearity and stability due to digital generation. In addition, the FPGA was programmed with two memory buffers to switch between two waveforms (long and short chirps) at the PRF rate for the two-channel operation.

The signal generation for the FM-CW system is performed by the AD9858 DDS (Analog Devices). This DDS operates at 1 GSPS; its reference clock is generated by a LO and phaselocked loop (PLL). Operation details of this DDS for an FM-CW radar are given in Cárdenas Mansilla and others (2010). The DDS can generate a wideband chirp from 0 to $400 \mathrm{MHz}$, with a high rate and high linearity due to a digital generation. High linearity frequency sweep generation is essential for FM-CW systems, because they are extremely sensitive to linearity errors in the frequency ramp, which produces range side-lobes and therefore resolution degradation (Daniels, 2004). High rate sweep generation is necessary for fast surveys, such as airborne radar systems.

\section{DATA ACQUISITION AND CONTROL}

Data acquisition was performed by the digital system shown in Figure 7. There are three analog-to-digital converters (ADCs), each associated with an FPGA, which perform the coherent integration for SNR improvement. One converter is a 12-bit, single channel at a sampling frequency of $45 \mathrm{MHz}$, which is employed for FM-CW IF digitalizing. The other two ADCs are 12-bit, dual-channel converters at a sampling frequency of $40.5 \mathrm{MHz}$, where each converter is used for each pulse-compression channel digitalizing.

Each channel of the pulse-compression receiver is converted to a baseband (in-phase and quadrature components) by an analog active quadrature demodulator. This requires a double LO frequency; therefore an oscillator/PLL circuit of $310 \mathrm{MHz}$ is used. The quadrature components of the baseband signal of each channel are digitized by 12-bit dual ADCs, after which each FPGA performs the coherent integration.

This digital system can perform 64-4096 coherent integration traces for the pulse-compression radar, and 64-256 traces of integrations for the FM-CW system. The trace length for the pulse-compression system is 2048 samples for each channel, and 4096 samples for the FM-CW system, which gives the pulse-compression radar a measurement range of $\sim 4 \mathrm{~km}$.

All the FPGAs are connected to an internal data bus, which is linked to an embedded computer running a modified Linux version. This computer is based on a Xilinx Virtex-4 FPGA (Suzaku SZ410, small form-factor general purpose embedded computer board). The main task of this computer is to transfer the data between the FPGAs and the main computer through an Ethernet link. Other tasks include the processing of the PPS signals and NMEA messages from the GPS and the other set-up peripherals, such as DDSs, oscillators/PLLs and the waveform and timing generator FPGA. 


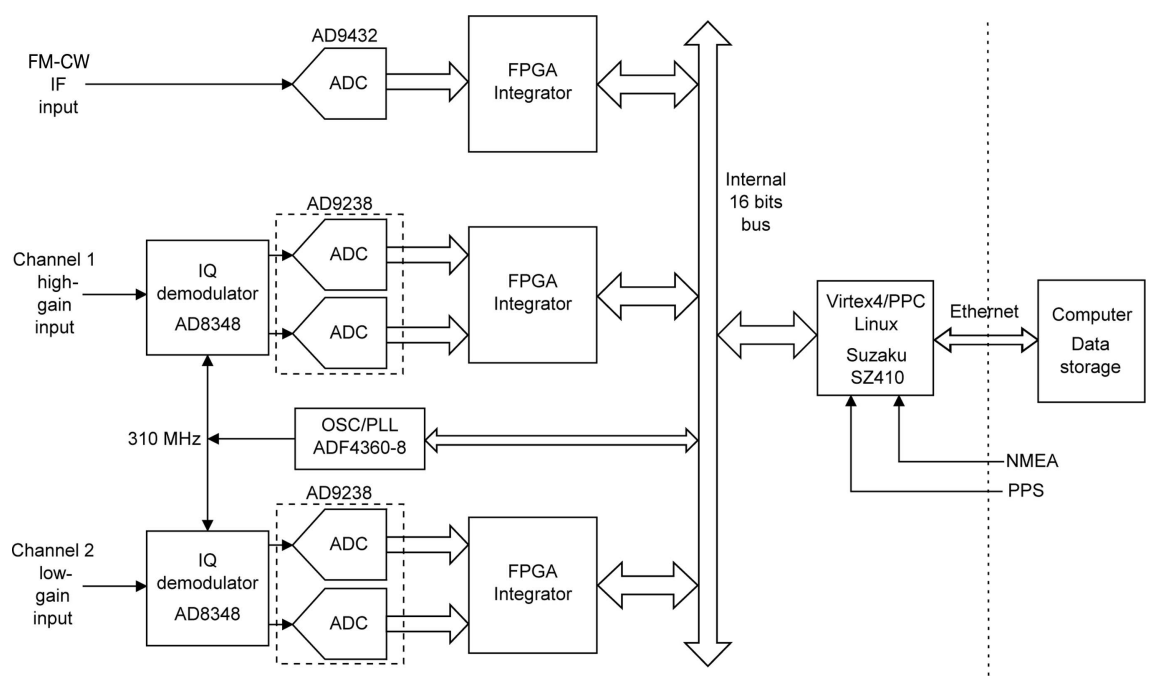

Fig. 7. Block diagram of the digital capturing system.

\section{DATA PROCESSING}

The pulse-compression and FM-CW raw data are stored in the field computer. After a survey, a custom software is used to apply the pulse compression algorithm and FM-CW range profile calculation. For pulse compression, we employ a fast Fourier transform (FFT) to obtain the frequency domain of each trace, then a matched filter is applied using the transmitted chirp waveform. Finally, an inverse FFT (IFFT) is used to obtain the compressed time-domain trace. For the FM-CW, a Hanning window is applied to each trace to reduce range side-lobes, followed by an FFT to obtain the range profiles. The next steps in the data processing (filtering, incoherent averaging, along-track interpolation and gain curves) are performed with REFLEXW software, developed by K.J. Sandmeier (Germany).

\section{FIELD TESTS AND DATA COLLECTION}

The complete system was tested during the ground-based campaign performed at Union Glacier (Figs 1 and 8) in December 2010. The campaign consisted of a tractor traverse, where pulling modules were used. The system rack was installed inside a rectangular module that included transmitter and receiver antennas on opposite sides. The radar system and computer were powered by a portable gasoline generator installed outside this module.

We used separated Yagi antennas for the pulse-compression radar transmitter and receiver. These antennas have a gain of $12 \mathrm{dBi}$ and $20 \mathrm{MHz}$ of bandwidth (Procom R2-10/I). The pulse-compression radar was set at $5 \mathrm{kHz}$ of PRF, 1024 traces of coherent integration and $20 \mathrm{~W}$ of output power. The survey average velocity was $5 \mathrm{~km} \mathrm{~h}^{-1}$, with which we obtained a trace of $\sim 0.6 \mathrm{~m}$ each with two-channel operation. The FM-CW radar used separated log-periodic antennas (receiver and transmitter), with $6 \mathrm{dBi}$ of gain and $0.2-$ $2.0 \mathrm{GHz}$ of frequency range operation (A-Info DS-20200). Operating at $10 \mathrm{kHz}$ of PRF, the maximum integration of traces (256) was used. In this configuration, a trace of $\sim 0.04 \mathrm{~m}$ each was obtained; the large amount of data was reduced with incoherent averaging during post-processing. We had to use this configuration of the FM-CW radar because the parameters were designed for airborne survey and we could not change the high-pass Gaussian filter in the receiver during the field operation. Furthermore, during the field campaign the radars could not be operated simultaneously due to an electromagnetic interference problem in the digital system that reset the embedded computer board in full operation. Thus, ice thickness and snow/firn measurements were performed separately. At the present time, the EMI interference has been resolved in laboratory tests by adding ferrite beads at the cables, improving the digital system shield and fixing poor grounds in this printed-circuit board.

Figure 9 shows a radargram obtained from the pulsecompression radar in two-channel operation, using an additional 16 incoherent stacking traces and $0.168 \mathrm{~m} \mathrm{~ns}^{-1}$ wave velocity (Glen and Paren, 1975) to convert the twoway travel time into depth. This $\sim 82 \mathrm{~km}$ long profile (L1 in Fig. 8) starts in the Ellsworth Plateau ( 1760 ma.s.l.) and ends at Union Glacier ( 700 ma.s.l.). In this profile, we

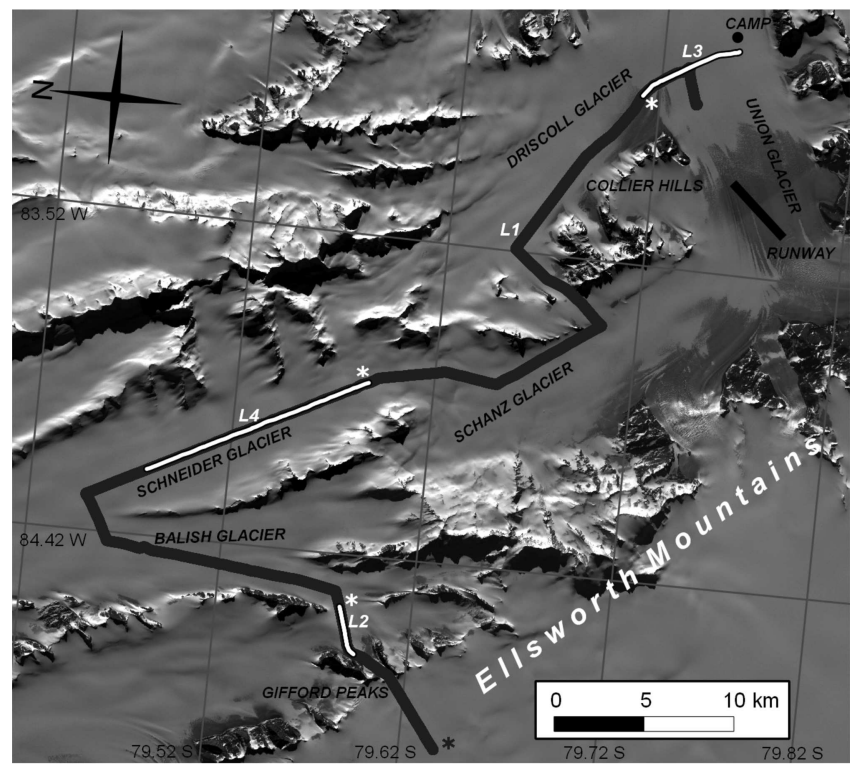

Fig. 8. Location map of Union Glacier, West Antarctica, based on an Advanced Spaceborne Thermal Emission and Reflection Radiometer (ASTER) mosaic. The ice thickness measurement route is shown in thick black line. FM-CW radar measurements are shown in thin white lines. A star symbol marks the beginning of each profile. 


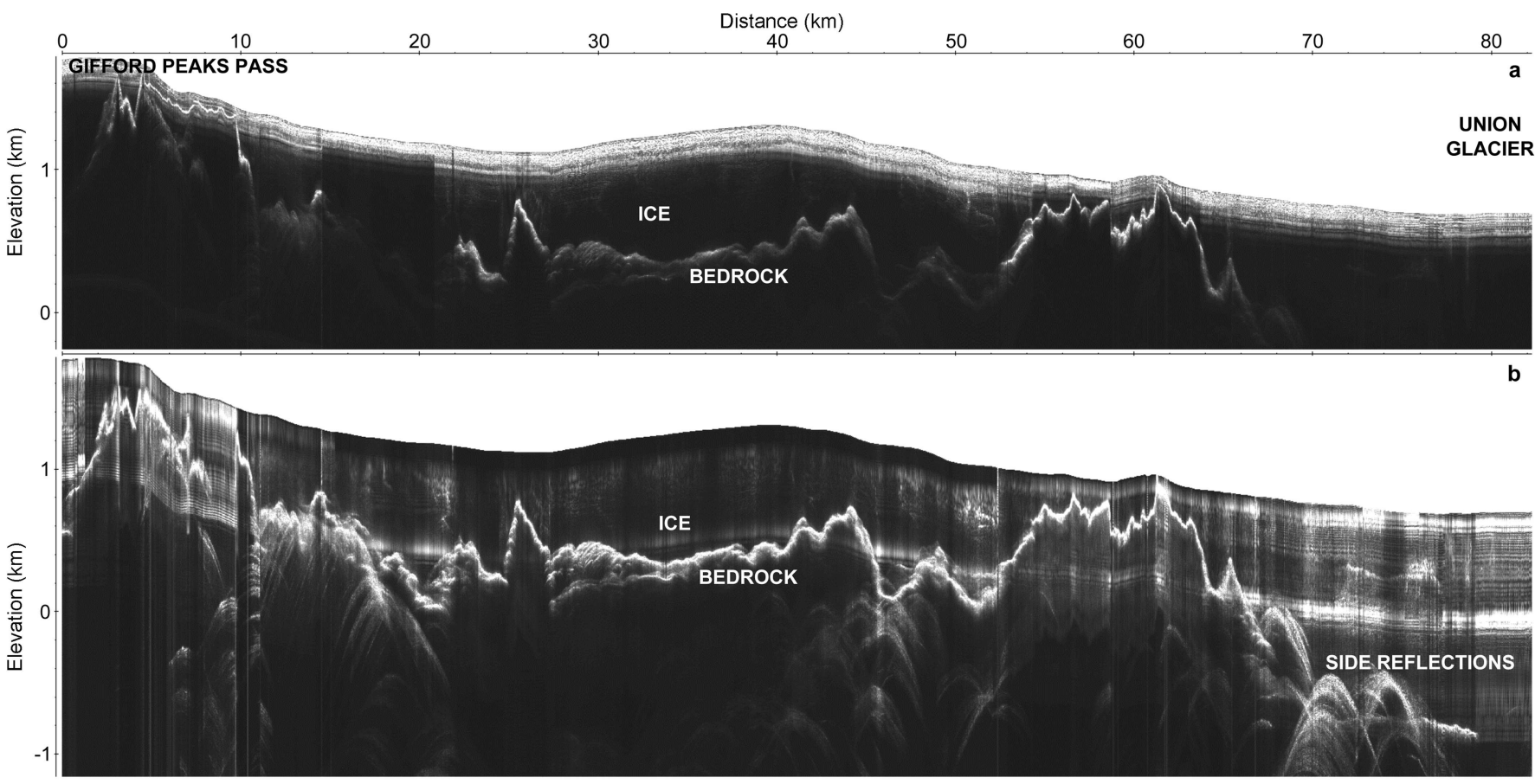

Fig. 9. Radargram obtained from the pulse-compression radar (L1 in Fig. 8). We surveyed through Balish, Schneider, Schanz, Driscoll and Union glaciers, starting at Ellsworth Plateau to Union Glacier. The depth axis is based on $0.168 \mathrm{~m} \mathrm{~ns}^{-1}$ wave velocity in ice. (a) Low-gain channel output. (b) High-gain channel output.

obtained ice thickness measurements for Balish, Schneider, Schanz and Driscoll glaciers, where a complex subglacial topography was observed. At the beginning of the profile, in the low-gain channel (Fig. 9a), the shallow ice in the Gifford Peaks pass can be identified, with a thickness of $\sim 45-140 \mathrm{~m}$. This is not visible in the high-gain channel (Fig. 9b) due to a blanking effect in the receiver. However, the low-gain channel cannot detect more than $1000 \mathrm{~m}$ of ice thickness. With this profile we measured maximum ice thicknesses of $1124 \mathrm{~m}$ at Balish Glacier, $904 \mathrm{~m}$ at Schneider Glacier, $1056 \mathrm{~m}$ at Schanz Glacier and $1514 \mathrm{~m}$ at Driscoll Glacier. At the end of the profile, there are some side reflections, probably from the Collier Hills. The maximum thickness detected was $1540 \mathrm{~m}$ at Union Glacier.

The profile shown in Figure 10 corresponds to a $2880 \mathrm{~m}$ long FM-CW radargram (L2 in Fig. 8) obtained for the Gifford Peaks pass. The survey took place from Balish Glacier to the Ellsworth Plateau. We used 64 incoherent stacking traces and $0.173 \mathrm{~m} \mathrm{~ns}^{-1}$ radar wave propagation velocity. This slightly higher wave velocity compensates for the high wave velocity in firn for full ice-depth profiles (Campbell and others, 2013). In the Gifford Peaks pass zone, ice thickness detected by the radar equated to $\sim 39-128 \mathrm{~m}$, differing from the pulse-compression radar because of the alternate pass route used. In the same profile, several firn areas with a maximum thickness of $\sim 120 \mathrm{~m}$ were detected. Additionally, the FM-CW radar was able to detect up to $\sim 350 \mathrm{~m}$ of ice thickness.

Figure 11 shows a $6150 \mathrm{~m}$ long profile of Union Glacier (L3 in Fig. 8). We set the system to 64 incoherent stacking traces and $0.189 \mathrm{~m} \mathrm{~ns}^{-1}$ wave velocity for the firn profiles (Campbell and others, 2013). The measurement starts at Driscoll Glacier and finds Union Glacier at $\sim 1000 \mathrm{~m}$ distance. At the beginning of Union Glacier, there are some crevasses indicated by increased noise in the radargram. In this profile, the firn-ice boundary is clearly visible, and we obtained a maximum firn thickness of $34 \mathrm{~m}$ at the end of the profile (close to the camp).

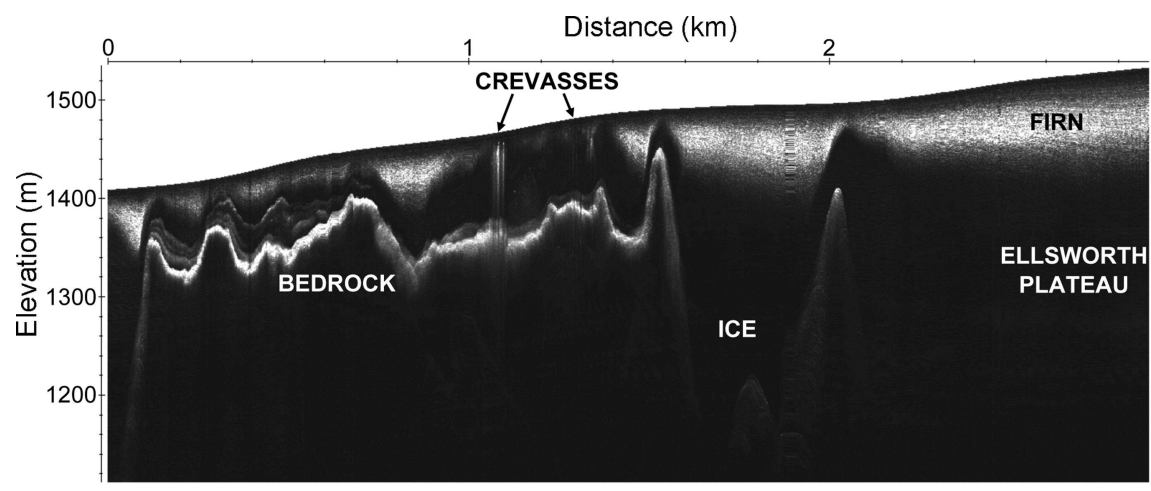

Fig. 10. Radargram from the FM-CW radar of the Gifford Peaks pass (L2 in Fig. 8), starting at Balish Glacier to Ellsworth Plateau. The radar wave velocity is $0.173 \mathrm{~m} \mathrm{~ns}^{-1}$ for firn-ice full depth, and the maximum range shown is $420 \mathrm{~m}$. 


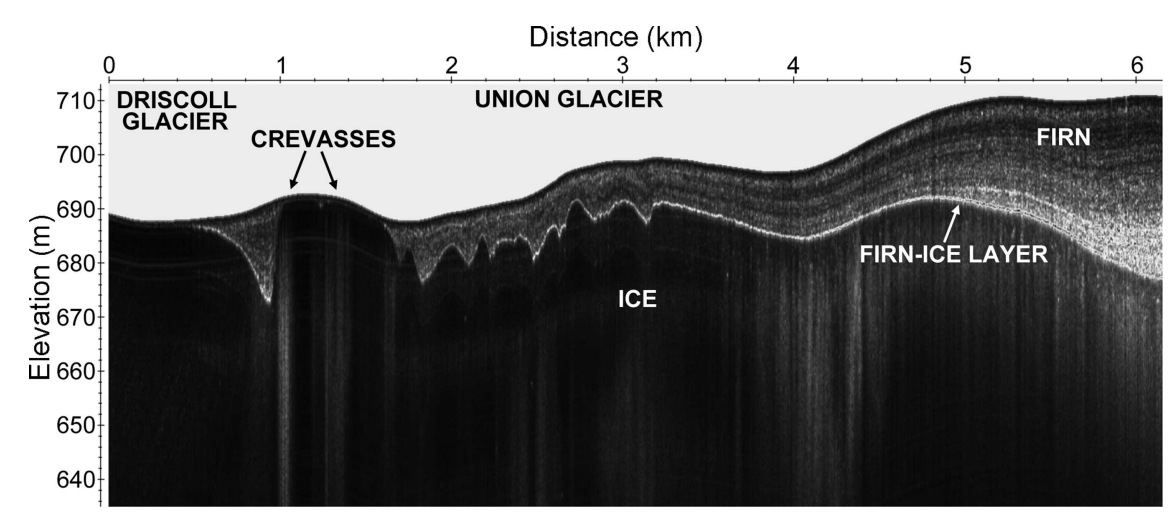

Fig. 11. Radargram from the FM-CW radar at Driscoll and Union Glaciers (L3 in Fig. 8), starting at Driscoll Glacier to Union Glacier. The maximum range shown is $78 \mathrm{~m}$, using a radar wave velocity of $0.189 \mathrm{~m} \mathrm{~ns}^{-1}$ for firn profiles.

Figure 12 shows an FM-CW radargram corresponding to the divide between Schanz and Schneider Glaciers (L4 in Fig. 8), where multiple firn layers are clearly visible down to $105 \mathrm{~m}$. The survey started from Schanz Glacier, extending throughout Schneider Glacier. The profile is $\sim 13 \mathrm{~km}$ long and was obtained using 128 incoherent stacking traces and a gain curve for amplitude compensation. The gain curve was obtained by envelope detection (a low-pass filter) of each trace. In this case we also used a radar wave velocity of $0.189 \mathrm{~m} \mathrm{~ns}^{-1}$ to calculate the measured range depth.

\section{DISCUSSION}

We calculated ice and snow depths assuming a constant radar wave velocity in three different scenarios (full deep ice, firn-ice and only firn). In general, it is assumed that ice thickness is best estimated for cold ice using wave velocities of $0.168 \mathrm{~ns}^{-1}$. However, in firn-ice and firn-only profiles there is some uncertainty in depth calculation due to electrical permittivity variation. Generally, snow and firn layers have a large variation of radar propagation wave velocity $\left(\sim 0.230-0.168 \mathrm{~m} \mathrm{~ns}^{-1}\right.$; Looyenga, 1965), which depends on the snow/firn density variation. Estimations of snow/firn density or common-midpoint measurements for wave velocity profile estimation could improve the range calculations in firn-ice and firn-only profiles.

In Table 1, we show that the resolution of the pulsecompression radar used here is $4.2 \mathrm{~m}$, which corresponds to the theoretical resolution using the wave velocity of $0.168 \mathrm{~m} \mathrm{~ns}^{-1}$ in ice and the $20 \mathrm{MHz}$ bandwidth. In fact, this resolution is degraded by range side-lobes in the compression processes, which could be improved by appropriate window functions. The ice thickness detected by this radar was $1540 \mathrm{~m}$ at Union Glacier, using only $20 \mathrm{~W}$ of the total transmitter peak power $(200 \mathrm{~W})$. The latter was enabled by employing high coherent integration (1024 traces), highgain antennas $(12 \mathrm{dBi})$ and long pulse chirp $(10 \mu \mathrm{s})$. An early version of this radar detected $2120 \mathrm{~m}$ in the Horseshoe Valley (Rivera and others, 2010). Since the pulsecompression radar presented in this paper is an improved version, we can expect at least similar performance, but more field tests are needed to determine the actual maximum detectable ice thickness. Results were satisfactory, but additional improvement could be made in the signal processing of the raw data to obtain clearer radargrams, for example focused synthetic aperture radar processing techniques in order to improve the along-track resolution (Legarsky and others, 2001; Peters and others, 2005).

In Figure 9, blanking effects at the receiver are indicated in the low-gain profile by the white area in the first $\sim 100-180 \mathrm{~m}$ of each trace. In the high-gain profile (Fig. 9a), blanking affects the first $\sim 850 \mathrm{~m}$. Only strong signals (e.g. bed returns) could be detected during the blanking interval, so internal layers were not detected at the blanking phase. Airborne measurements could avoid the

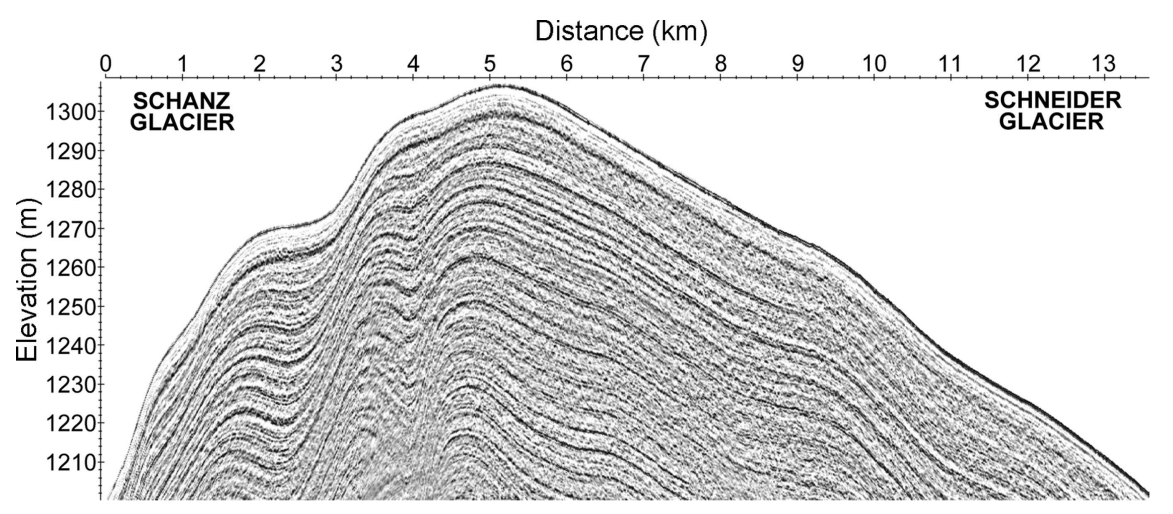

Fig. 12. Radargram from the FM-CW radar at the divide between Schanz and Schneider Glaciers (L4 in Fig. 8), where internal layers are observed. We surveyed from Schanz Glacier to Schneider Glacier. The maximum range shown is $105 \mathrm{~m}$, using a radar wave velocity of $0.189 \mathrm{~m} \mathrm{~ns}^{-1}$ for firn profiles. 
blind range produced by the blanking circuit, so this type of platform will be tried in future Antarctic campaigns.

The benefits of the system and its deployment include low power consumption $(\sim 80 \mathrm{~W}$, excluding the laptop computer) and the overall weight (only $\sim 35 \mathrm{~kg}$ including the rack), as well as its relatively low cost of total construction ( US\$20000) compared to, for example, the cost of acquiring commercial modules for the equipment. We reduced costs, power consumption and weight mainly by designing our own 200 W RF power amplifier and our digital capturing and control systems. Further improvements could be made in these sections of the radar, optimizing design and power consumption and using current modern electronic components to optimize the size of the system.

Among the advantages for the system performance are the ability to generate surveys with high PRF ( $10 \mathrm{kHz}$ maximum) and low coherent integration (64 traces minimum per channel); therefore this radar system has a sufficient rate of data capture to be installed on board airborne platforms. The FM-CW radar can detect the bedrock up to $\sim 350 \mathrm{~m}$ in cold ice with high resolution, improving the bedrock detection from the pulse-compression radar when surveying shallow ice. Furthermore, due to the high resolution and high PRF, the FM-CW system allows crevasse detection.

Further field tests are needed to prove that this system can work with the pulse-compression and FM-CW radars simultaneously without interference or received signal degradation. These tests will be undertaken this austral summer.

\section{CONCLUSIONS}

We have presented the design of a low power consumption, low-weight and low-cost radar system, able to measure Antarctic ice thickness and snow/firn internal layers. Data collected in the Union Glacier ground-based campaign proved that this system is an appropriate instrument to detect subglacial topography as well as measure multiple internal snow/firn layers and the snow/ice boundary layer. Ice thickness of $1540 \mathrm{~m}$ and firn thickness of $120 \mathrm{~m}$ were detected with strong return levels; data that enable us to improve the glaciological baseline of Union Glacier and neighboring glaciers. We are making several improvements to our signal-processing algorithms in order to reduce clutter and increase SNR and along-track resolution. More field tests are already planned to take place in Antarctica during this austral summer, when a simultaneous FM-CW and a pulse-compression radar operation will be undertaken. Due to the high data-capture rate capacity, the radars developed are suitable for airborne surveys, allowing larger areas to be surveyed more efficiently and in detail. In order to confirm this, we expect to mount the system on an airplane, using transmitter and receiver dipole array antennas for the pulsecompression radar and a patch antenna array for the FM-CW radar system. Furthermore, we expect to extend the bandwidth of the FM-CW radar for better snow/firn-layer resolution detection, as well as a design optimization to reduce the overall weight/size and power consumption for future applications in UAV systems.

\section{ACKNOWLEDGEMENTS}

The field campaigns were funded and supported by Antarctic Logistics and Expeditions (ALE). CECs is funded by the Chilean Government through the Centers of Excellence Base
Financing Program of Comisión Nacional de Investigación Científica y Tecnológica de Chile (CONICYT). Andrés Rivera is a Guggenheim fellow.

\section{REFERENCES}

Bingham RG and Siegert MJ (2007) Radio-echo sounding over polar ice masses. J. Environ. Eng. Geophys., 12(1), 47-62 (doi: 10.2113/ JEEG12.1.47)

Blake W and 6 others (2008) A VHF radar for deployment on a UAV for basal imaging of polar ice. In Proceedings of the IEEE International Geoscience and Remote Sensing Symposium (IGARSS 2008), 7-11 July 2008, Boston, MA, USA, Vol. 4. Institute of Electrical and Electronics Engineers, Piscataway, NJ, 498-501

Campbell S and 6 others (2013) Radar-detected englacial stratigraphy in the Pensacola Mountains, Antarctica: implications for recent changes in ice flow and accumulation. Ann. Glaciol., 54(63 Pt 1), 91-100 (doi: 10.3189/2013AoG63A371)

Cárdenas Mansilla CA, Jenett $M$, Schünemann $K$ and Winkelmann J (2010) Sub-ice topography in Patriot Hills, West Antarctica: first results of a newly developed high-resolution FM-CW radar system. J. Glaciol., 56(195), 162-166 (doi: 10.3189/ 002214310791190839)

Daniels DJ (2004) Ground penetrating radar, 2nd edn. Institution of Electrical Engineers, London

Glen JW and Paren JG (1975) The electrical properties of snow and ice. J. Glaciol., 15(73), 15-38

Gogineni S, Chuah T, Allen C, Jezek K and Moore RK (1998) An improved coherent radar depth sounder. J. Glaciol., 44(148), 659-669

Gogineni S and 9 others (2001) Coherent radar ice thickness measurements over the Greenland ice sheet. J. Geophys. Res., 106(D24), 33 761-33 772 (doi: 10.1029/2001JD900183)

Hellmer H, Kauker F, Timmermann R, Determann J and Rae J (2012) Twenty-first-century warming of a large Antarctic iceshelf cavity by a redirected coastal current. Nature, $\mathbf{4 8 5}$ (7397), 225-228 (doi: 10.1038/nature11064)

Kanagaratnam P (2002) Airborne radar for high-resolution mapping of internal layers in glacial ice to estimate accumulation rate. (PhD thesis, University of Kansas)

Kanagaratnam P, Gogineni SP, Ramasami V and Braaten D (2004) A wideband radar for high-resolution mapping of near-surface internal layers in glacial ice. IEEE Trans. Geosci. Remote Sens., 42(3), 483-490 (doi: 10.1109/TGRS.2004.823451)

Legarsky JJ, Gogineni P and Atkins TL (2001) Focused syntheticaperture radar processing of ice-sounder data collected over the Greenland ice sheet. IEEE Trans. Geosci. Remote Sens., 39(10), 2109-2117 (doi: 10.1109/36.957274)

Looyenga H (1965) Dielectric constant of heterogeneous mixtures. Physica, 31(3), 401-406 (doi: 10.1016/0031-8914(65)90045-5)

Lythe MB, Vaughan DG and BEDMAP consortium (2001) BEDMAP: a new ice thickness and subglacial topographic model of Antarctica. J. Geophys. Res., 106(B6), 11335-11351 (doi: 10.1029/2000JB900449)

Mahafza BR (2000) Radar systems analysis and design using MATLAB. Chapman and Hall, Boca Raton, FL

Namburi SPV (2003) Design and development of an advanced coherent radar depth sounder. (MS thesis, University of Kansas)

Panzer B and 8 others (2013) An ultra-wideband, microwave radar for measuring snow thickness on sea ice and mapping nearsurface internal layers in polar firn. J. Glaciol., 59(214), 244-254 (doi: 10.3189/2013JoG12J128)

Peters ME, Blankenship DD and Morse DL (2005) Analysis techniques for coherent airborne radar sounding: application to West Antarctic ice streams. J. Geophys. Res., 110(B6), B06303 (doi: 10.1029/2004JB003222)

Plewes LA and Hubbard B (2001) A review of the use of radio-echo sounding in glaciology. Progr. Phys. Geogr., 25(2), 203-236 (doi: 10.1177/030913330102500203) 
Raney RK, Leuschen C and Jose M (2008) Pathfinder Advanced Radar Ice Sounder: PARIS. In Proceedings of the IEEE International Geoscience and Remote Sensing Symposium (IGARSS 2008), 7-11 July 2008, Boston, MA, USA, Vol. 3. Institute of Electrical and Electronics Engineers, Piscataway, NJ, 346-349

Remy MA, de Macedo KAC and Moreira JR (2012) The first UAVbased P- and X-band interferometric SAR system. In Proceedings of the IEEE International Geoscience and Remote Sensing Symposium (IGARSS 2012), 22-27 July 2012, Munich, Germany. Institute of Electrical and Electronics Engineers, Piscataway, NJ, 5041-5044

Rivera A, Zamora R, Rada C, Walton J and Proctor S (2010) Glaciological investigations on Union Glacier, Ellsworth
Mountains, West Antarctica. Ann. Glaciol., 51(55), 91-96 (doi: 10.3189/172756410791392772)

Rodríguez-Morales F and 17 others (2013) Advanced multifrequency radar instrumentation for polar research. IEEE Trans. Geosci. Remote Sens., 52(5), 2824-2842 (doi: 10.1109/ TGRS.2013.2266415)

Vaughan DG, Rivera A, Woodward J, Corr H, Wendt J and Zamora $R$ (2007) Topographic and hydrological controls on Subglacial Lake Ellsworth, West Antarctica. Geophys. Res. Lett., 34(18), L18501 (doi: 10.1029/2007GL030769)

Waite AH and Schmidt SJ (1962) Gross errors in height indication from pulsed radar altimeters operating over thick ice or snow. Proc. Inst. Radio Eng., 50(6), 1515-1520 (doi: 10.1109/ JRPROC.1962.288195) 